\title{
Possibilidades socioambientais e interdisciplinares da cidadania a partir do que dizem alunos e professores de uma escola pública de ensino fundamental em Salvador- \\ Bahia
}

Isabelle Pedreira Déjardin*

Universidade Federal da Bahia

Resumo O objetivo deste artigo é analisar a cidadania na formação de alunos de uma escola pública de ensino fundamental do bairro do Cabula, em Salvador, Bahia. A pesquisa de campo foi realizada entre os meses de setembro a dezembro de 2014. Foram aplicadas entrevistas com quatro professores das turmas do turno matutino dos Temas Transversais de Cidadania, Meio Ambiente e Ciência e Tecnologia. Questionários mistos foram aplicados com um total de quarenta alunos selecionados entre as respectivas turmas - dez por turma. Os resultados apontaram desafios e possibilidades socioambientais a partir da interdisciplinaridade do tema proposto.

PALAVRAS-ChaVE: Cidadania; Educação; Meio ambiente. 


\title{
Social-environmental and interdisciplinary possibilities of citizenship from what students and teachers say at a public elementary school, in Salvador the capital of Bahia State
}

\begin{abstract}
The aim of this paper is to analyze citizenship in formal education process of students of a public elementary school in Cabula's neighborhood, in Salvador the capital of Bahia State. The research field occurred between September and December 2014. Interviews were applied to four teachers from the morning shifty classes of Citizenship, Environment, Science, and Technology Main Themes. The questionnaires were applied to forty students selected from the respective classes, ten per class. The results pointed social-environmental challenges and possibilities from the interdisciplinarity of the proposed theme.
\end{abstract}

KEYWORDS: Citizenship; Education; Environment.

\section{Introdução}

Um dos principais objetivos da formação de alunos do ensino fundamental das escolas públicas brasileiras é formar cidadãos capazes de construir valores nas sociedades, desenvolver habilidades para a vida e o trabalho e promover atitudes de transformação da realidade socioambiental. A importância que se confere à formação de cidadãos está explícita nos objetivos gerais do ensino fundamental, nos tópicos dos Parâmetros Curriculares Nacionais (PCN), na função da escola, nos conteúdos, nos temas transversais e nas orientações didáticas. Nesse quesito, tanto os documentos públicos oficiais quanto as práticas educativas contemporâneas buscam promover a ideia da formação de sujeitos para a cidadania, ou a formação de sujeitos cidadãos. Para tanto, tem-se a Lei de Diretrizes e Bases da Educação Nacional (LDB - Lei no 9.394/1996), conhecida como Lei Darcy Ribeiro, que em seu artigo 22 indica que a educação básica da qual o ensino fundamental é parte integrante deve assegurar a todos os estudantes a formação comum indispensável para o exercício da sua cidadania, fornecendo-lhes meios para progredir no trabalho e em estudos posteriores.

Em relação aos educadores, é sabido que muitos conseguem fazer a diferença em sala de aula, buscando, por um lado, alternativas para o conhecimento construído e socializado sobre cidadania nos contextos escolares e, de outro, o aperfeiçoamento de novas perspectivas inclusivas em suas práticas educativas e curriculares. Sobre os $\mathrm{PCN}$ e as atividades pedagógicas exercidas pelos docentes, a prerrogativa básica para os professores do terceiro e quarto ciclo do ensino fundamental $\left(6^{\circ}, 7^{\circ}, 8^{\circ}\right.$ e $9^{\circ}$ ano, dois anos para cada ciclo) envolve, basicamente, os seguintes aspectos: apoio às discussões e ao desenvolvimento do projeto educativo nas escolas; reflexão sobre a prática pedagógica e o planejamento de aulas; análise; seleção de materiais didáticos e recursos tecnológicos; contribuição para formação docente e atualização profissional. Para os alunos, o que se espera é que esses parâmetros incluam a necessidade de construção de uma referência curricular nacional, permitindo aos discentes o acesso permanente aos 
Possibilidades socioambientais e interdisciplinares da cidadania a partir do que dizem alunos e professores de uma escola pública de ensino fundamental em Salvador-Bahia

conhecimentos para a construção da cidadania, com ênfase nos dois principais pilares de estruturação dos PCN: a interdisciplinaridade e a contextualização.

Quanto às questões socioambientais da contemporaneidade, em geral, surgem associadas a orientações e práticas de educação ambiental, configurando-se nas produções acadêmicas sobre contextos escolares e nos documentos oficiais. Tais premissas podem ser conferidas nos documentos que compõem os PCN e os Temas Transversais das escolas públicas brasileiras, elaborados pelo Ministério da Educação (MEC). Assim, ainda que de forma fragmentada, a cidadania e as questões socioambientais vêm sendo incorporadas nos processos educativos, ora por meio dos documentos e propostas oficiais das políticas públicas que norteiam o sistema educacional brasileiro, ora nas propostas contidas nos currículos e práticas educativas recorrentes. Aliás, a própria discussão dos PCN ocorreu sobre amplas vertentes políticas, sociais, econômicas e históricas, suscitando, no Brasil, os debates globais sobre as questões socioambientais, que é o caso dos conteúdos elaborados nesses documentos.

Nesse sentido, cumpre esclarecer que os PCN não são a única fonte disponível de expressão de cidadania ou de meio ambiente implicadas nas atividades didáticas e curriculares das escolas. Essa é uma crítica que recai no modelo rígido de currículo que apresenta caráter disciplinar e fragmentado. Currículo vem do latim Curriculum, significando trajetória, percurso, travessia, com pontos de partida e chegada, abarcando a filosofia escolar, as ideologias, a diversidade de conhecimentos e as experiências educativas. Conjuntamente aos documentos públicos oficiais brasileiros, dentre os quais se encontram os PCN, existem propostas educativas que buscam problematizar questões e interesses de forma a integrar comunidades e realidades locais, seja por meio da multi/interdisciplinaridade, seja pelas relações didático-transformadoras que se desenvolvem em sala de aula. Como exemplo, cita-se a importância conferida aos Projetos Políticos Pedagógicos (PPP) das unidades escolares, nos quais diferentes propostas envolvendo ação, reflexão e participação curricular podem se concretizar em âmbito local.

Diante dessas considerações, uma pesquisa de campo foi desenvolvida entre os meses de setembro a dezembro de 2014 em uma escola pública de ensino fundamental situada no bairro do Cabula, em Salvador, Bahia. Um primeiro questionamento emergiu: como essa cidadania envolve valores ambientais? Sabe-se que o bairro do Cabula e entorno vêm passando por diversas transformações urbanas, sociais, econômicas, políticas, territoriais e ambientais nestas últimas décadas, com impactos diretos sobre a organização, a cultura e os ecossistemas locais (FERNANDES; PENA, LIMA, 2013). Nesse cenário, o objetivo do presente artigo é analisar conceitos de cidadania em estreita aproximação com o meio ambiente, a partir da formação advinda dos Eixos Temáticos dos Temas Transversais do ensino fundamental, especificamente os de Cidadania, Meio Ambiente e Ciência e Tecnologia. Assim sendo, na próxima seção, são analisados os resultados das entrevistas e questionários aplicados com alunos e professores da unidade de ensino, bem como os referenciais teóricos que subsidiam o escopo empírico. Desse modo, explicita-se uma sistematização dos desafios e possibilidades socioambientais emergidos da interdisciplinaridade do tema proposto. 


\section{Cidadania e meio ambiente: aproximações contextuais}

Para Ednir e Macedo (2011), no contexto de uma educação global, a cidadania planetária é aquela que assume algumas dimensões nos currículos de crianças e jovens, tais como os direitos humanos; a justiça social; a diversidade cultural; a resolução de conflitos; a interdependência; a sustentabilidade; a cidadania global e a percepção dos valores associados com cada um destes conceitos chave. A cidadania planetária abarca assim a concepção de que os problemas de âmbito local estão inseridos em um contexto de realidade planetária, fazendo com que os alunos se percebam como cidadãos globais, planetários, logo cidadãos do mundo (EDNIR; MACEDO, 2011). Na América Latina em geral e, no Brasil, em particular, a postura mais difundida sobre cidadania e que ainda persiste é aquela que enfatiza o reconhecimento dos direitos do cidadão, impedindo, portanto, o avanço da construção de uma cidadania relacionada com noções de território, ecologia, pertencimento e identidade dos sujeitos (GUDYNAS, 2009).

Segundo Gadotti (2001), a ecopedagogia apresenta as condições necessárias para agregar valor à cidadania planetária, não se opondo à educação ambiental, mas correlacionando-se a esta. $\mathrm{O}$ autor retoma a noção de cidadania planetária introduzida por Francisco Gutierrez e Cruz Prado nos anos 1990, período de conceituação da ecopedagogia com base na Carta da Terra. Conforme Gadotti (2001), a cidadania ambiental torna-se uma cidadania planetária na medida em que inclui a dimensão social, na qual os seres humanos e o planeta sejam a sua maior prioridade, reconhecendo que se trata de um ponto de referência ética indissociável da ecologia e da civilização planetária. A cidadania planetária associa-se, em geral, com a ideia de sustentabilidade, mas amplia a discussão para outras vertentes éticas, como os processos educativos, manifestando-se em diferentes expressões, como a nossa humanidade comum, a unidade na diversidade, o nosso futuro comum, a nossa pátria comum (OLIVEIRA, 2014).

Nesse sentido, e diante da premência em se tratar a dimensão socioambiental no processo educativo, as escolas assumem como um de seus principais objetivos o aprendizado voltado para a formação socioambiental cidadã (DIAS; CARNEIRO, 2012). Conforme as autoras, a transformação sociocultural é um dos passos dados para o desenvolvimento do exercício da cidadania, na qual a educação ambiental se posiciona como base crítica do processo de pertencimento e na construção da identidade dos sujeitos. A cidadania socioambiental se constrói a partir de algumas conquistas já consolidadas na sociedade, como a democracia cidadã e a cidadania participativa. Em nível local, a cidadania socioambiental insere-se em um contexto de reconfiguração da cidadania por meio das mudanças culturais, incluindo uma reflexão sobre a escola, a comunidade, o bairro e as relações com a natureza (DIAS; CARNEIRO, 2012). Importante destacar que, não raras vezes, nas escolas, tais relações se esvaziam de sentidos tendo em vista a natureza surgir caracterizada mais pelos seus aspectos biofísicos como água, relevo, solo e ar do que pelas relações desenvolvidas entre indivíduos, sociedades e ecossistemas. Essa dicotomia nas representações está contida também nos debates sobre cidadania e meio ambiente do séc. XXI. Conforme ressalta Gudynas (2009): 
Possibilidades socioambientais e interdisciplinares da cidadania a partir do que dizem alunos e professores de uma escola pública de ensino fundamental em Salvador-Bahia

[...] o conceito convencional de cidadania é outra das expressões de uma visão dual que diferencia os seres humanos da Natureza. Cidadania inevitavelmente refere-se à cidade, a uma 'polis', aquela que está por fora da Natureza, que pode ser dividida em componentes a serem manipulados e aproveitados. O cidadão enquanto 'civilizado' deve controlar e aproveitar os espaços silvestres ou 'selvagens'. Estas são posturas próprias da modernidade, na qual as concepções de cidadão e ambiente se determinam mutuamente (tradução nossa) ${ }^{1}$.

De acordo com Dias e Carneiro (2012, p. 9), as questões relativas ao meio ambiente devem ser problematizadas desde os contextos dos alunos que se fazem sujeitos, considerando a escola como espaço sócio pedagógico que busca a formação cidadã, sendo "fundamental que as questões socioambientais relevantes do entorno da escola sejam discutidas na escola, favorecendo a problematização da realidade". Sendo assim, nesse contexto teórico-metodológico inicial de cidadania ampliada com as questões de meio ambiente, adentra-se na análise do que dizem alunos e professores da escola pública aqui referida.

\section{Resultados e discussão}

\section{Metodologia: lócus, técnicas e sujeitos de pesquisa}

A escolha pela Escola Estadual Visconde de Itaparica como lócus de pesquisa deu-se de forma não probabilística, dada a própria abordagem qualitativa adotada. Esse tipo de amostragem se caracteriza pela utilização de critérios escolhidos pelo pesquisador, não apresentando fundamentação matemática ou estatística, dependendo unicamente de critérios pessoais e subjetivos (GIL, 1999). Essa unidade educacional foi fundada em 1954 por meio do exército brasileiro, e está localizada na Rua Silveira Martins, s/n, bairro do Cabula, ao lado do 19º Batalhão de Caçadores (19 BC), com exuberante presença de mata atlântica no local. Foram aplicadas ${ }^{2}$ entrevistas semiabertas (VERGARA, 2009) com quatro professores das turmas do turno matutino dos Eixos Temáticos citados: dois professores de $6^{\circ}$ ano (Meio Ambiente), um de $8^{\circ}$ ano (Cidadania) e um de $9^{\circ}$ ano (Ciência e Tecnologia); com 40 alunos selecionados entre as respectivas turmas - 10 por turma - foram aplicados questionários mistos (VERGARA, 2009).

Durante o período de desenvolvimento da pesquisa de campo, fez-se também observação (GIL, 1999) das aulas e da dinâmica escolar. As perguntas sobre cidadania nos questionários aplicados aos alunos foram: $\mathrm{O}$ que você entende por cidadania? O que são direitos e deveres do cidadão? As perguntas sobre cidadania nas entrevistas realizadas com os professores foram: Qual a sua concepção sobre cidadania? Quais os meios e estratégias em que se baseia para discutir esse tema com os alunos em sala de aula? Dos 40 alunos que responderam aos questionários, 95\% disseram morar na localidade do Cabula e entorno, estando divididos da seguinte forma: 45\% em São Gonçalo do Retiro; 17,5\%, no Cabula; 17,5\% em Engomadeira; 5\% em Estrada das Barreiras; $5 \%$ em Nova Sussuarana; $5 \%$ em outros bairros do entorno do Cabula e 5\% em outros bairros de Salvador. Do total de alunos respondentes, $57,5 \%$ foram do sexo masculino e $42,5 \%$ do sexo feminino. A faixa etária predominante foi a de 13-14 anos 
(42,5\%), seguida da faixa de 15-16 anos (37,5\%). As outras duas faixas etárias com percentuais menores foram: $10-12$ anos (15\%) e mais de 16 anos (5\%). Assim, participaram dos questionários 20 alunos de duas turmas de $6^{\circ}$ ano, do Eixo Temático de Meio Ambiente; 10 alunos de uma turma de $8^{\circ}$ ano, do Eixo Temático de Cidadania; e 10 alunos de uma turma de $9^{\circ}$ ano, do Eixo Temático de Ciência e Tecnologia, temas escolhidos pela relevância apresentada para a pesquisa.

Sobre os quatro professores que participaram da pesquisa, três foram do sexo feminino e um do sexo masculino, todos na faixa etária de 41-50 anos. A formação acadêmica em nível de graduação deste grupo foi de $75 \%$ em Letras e de $25 \%$ em Pedagogia, sendo que a formação acadêmica em nível de pós-graduação dividiu-se em duas especializações: 75\% do curso de Metodologia do Ensino da Pesquisa e Extensão em Educação e 25\% do curso de Educação Inclusiva. Dos quatro professores pesquisados, metade possuía até um ano de tempo de docência na escola; a outra metade, mais de 10 anos. Na pesquisa, os alunos estão representados de A1 a A40, e os professores como P1, P2, P3 e P4, como exemplificados a seguir:

$$
\begin{aligned}
& \text { P1 }-6^{\circ} \text { ano, Turma A/ Eixo Temático de Meio Ambiente; } \\
& \text { P2 }-9^{\circ} \text { ano, Turma C/ Eixo Temático de Ciência e Tecnologia; } \\
& \text { P3 }-6^{\circ} \text { ano, Turma B/ Eixo Temático de Meio Ambiente; } \\
& \text { P4 }-8^{\circ} \text { ano, Turma A/ Eixo Temático de Cidadania. }
\end{aligned}
$$

\section{Análise dos resultados}

Quando questionados sobre os meios em que se baseiam para discutir o tema da cidadania com os alunos em sala de aula, P2 e P3 responderam, respectivamente:

Para discutir esses assuntos com meus alunos eu utilizo... um dos meios que eu mais utilizo é a internet e também algumas revistas que falam sobre meio ambiente (P2).

Os PCN, pra gente ter uma base daquilo que vai ser passado pelas disciplinas e pesquisar todo o material que a gente possa encontrar a respeito dos assuntos $(\mathrm{P} 3)$.

P3 faz uso dos PCN, lendo o material disponibilizado pela escola e também pesquisa outras fontes com alguns recursos para discussão em sala de aula. P2 não cita os PCN como meio, mas informa que se atualiza na internet, buscando revistas sobre o tema da cidadania. Em seu Eixo Temático de Ciência e Tecnologia do $9^{\circ}$ ano, a cidadania não é um tema recorrente nos planos de aula e ensino, evidenciando uma concepção prévia de que esses alunos já tenham passado pela formação do tema no ano precedente, através do Eixo Temático de Cidadania. Para P4, apesar da importância dos PCN e dos livros didáticos servirem de norte na busca de conteúdos de cidadania, estes não precisam ser as únicas fontes de informação e conhecimento:

Os meios que eu utilizo: primeiramente, eu me baseio nos $\mathrm{PCN}$, me baseio também no livro didático, como eu sou professora também de língua portuguesa, eu utilizo muito algumas informações, alguns textos que me são fornecidos pelo livro didático de português, mas 
Possibilidades socioambientais e interdisciplinares da cidadania a partir do que dizem alunos e professores de uma escola pública de ensino fundamental em Salvador-Bahia

principalmente a gente tem um norte a seguir, não ficam as coisas soltas, e eu trabalhando dentro de cidadania, ah, o que eu quero, eu trabalho também com o norte que o governo nos fornece, então ele diz que a gente tem que trabalhar cidadania, o conceito de cidadania, direitos e deveres, diz que a gente tem que trabalhar com informações da sociedade, inclusão e exclusão social, com direitos humanos, então eu trabalho o ECA, consumo e consumismo, por isso que eu trabalho os oito $\mathrm{R}$ do consumo consciente, pode trabalhar com movimentos sociais, cidadania e políticas públicas, de saúde, educação, segurança (P4).

P4 compartilha e reflete a cidadania em sala de aula com base nos documentos oficiais, sendo preferível seguir os direcionamentos oferecidos pelos PCN e pelos livros didáticos que utiliza também nas aulas de português, para "não deixar as coisas soltas", sem um norte ou rumo a tomar. Quando a cidadania se expande para outras fronteiras, caso das áreas da saúde, do trabalho, dos movimentos sociais, da educação ambiental, das políticas públicas e da segurança, é possível constatar uma proposta interdisciplinar e multirreferencial (FRÓES BURNHAM, 2006) nesse processo educativo, promovendo-se um intercâmbio entre essas áreas para a construção de novos desafios, conhecimentos e práticas democráticas de cidadania. Nesse percurso de possibilidades, a fala de $\mathrm{P} 4$ reflete uma cidadania participativa e ativa, não se detendo apenas nos documentos oficiais, buscando como alicerce a inclusão social de seus atores sociais. Dos quatro professores que participaram das entrevistas, três recorreram aos direitos e deveres do cidadão para explicar o que entendiam sobre cidadania (P2, P3 e P4). A seguir, dois desses relatos:

Cidadania eu acho que é uma disciplina em que todos os professores devem estimular o aluno em sala de aula, para que eles conheçam os seus direitos, mas também os seus deveres (P2).

Cidadania é o exercício dos direitos das pessoas, de conhecer seus direitos e seus deveres também, e conviver pacificamente, lutando, mas conquistando pacificamente pelos seus direitos (P3).

De acordo com P3, cidadania é o exercício e a conquista pacífica dos direitos das pessoas que lutam; em sua fala, a palavra "pacífica" emana um sentido brando de luta. A fala de P3 aproxima-se da definição conceitual cujo principal mote é a luta política perante conflitos reais, em que os pressupostos básicos da construção da cidadania devem partir dos próprios cidadãos, para a validação e conquista desses mesmos direitos (BRASIL, 2005). Para P2, cidadania é uma disciplina em que os professores devem estimular os alunos a conhecer seus direitos e deveres. Entretanto, há que se considerar que se for vista apenas como disciplina, acaba se restringindo às grades curriculares, acarretando a perda de seu caráter interdisciplinar e transversal, características preconizadas pelos próprios $\mathrm{PCN}$ e pelos documentos oficiais norteadores (BRASIL, 1998). Segundo Severo (2008), formar cidadãos é muito mais do que um simples tema a ser declarado pelos documentos oficiais, tendo em vista pretender abordar diversos assuntos e por estar contida nos conteúdos e nas relações entre os Temas Transversais e as práticas cidadãs. Diante dessa tarefa e dos objetivos a que se propõe, seria incoerente reduzi-la a uma prática disciplinar, conforme argumentou P2. 
Cidadania é você se reconhecer como cidadão, exercer a sua função política, dentro do município, da cidade onde você vive e, principalmente, dentre outras coisas, você ter interação com o próximo, e praticar as coisas que são feitas na cidade, para que você viva num ambiente consolidado com a população (P1).

De acordo com a resposta de P1, a função política da cidadania emana de uma perspectiva citadina, na qual se garantem aos indivíduos os direitos de primeira geração (civis e políticos), assegurando-lhes também uma participação consolidada com o restante da população. Segundo Gudynas (2009), essa proposta de cidadania exercida exclusivamente de dentro da polis (cidade) acaba deixando a natureza de fora. $\mathrm{Na}$ fala de $\mathrm{P} 1$, a interação com o próximo pode levar a crer que o exercício dessa função política só pode ser efetivado em relação a outrem se este indivíduo se fizer detentor pleno de direitos.

Cidadania pra mim é você na verdade exercer o seu direito, é atividade, é a expressão da nossa atividade, dos nossos direitos, dos nossos deveres, é exercer esse papel de cidadão, de ter os direitos plenos, em relação à sociedade, ao cuidado, com a vida do outro, do meio ambiente, como eu expliquei antes o meio ambiente é o local onde a gente vive, mas em relação ao nosso planeta, é o nosso planeta Terra, é o nosso ambiente (P4).

Assim, tal como P2 e P3, P4 também recorre aos direitos e deveres do cidadão para explicar o que entende por cidadania. Todavia, apresenta uma visão ampliada, afirmando que é possível concebê-los abarcando toda a sociedade, no sentido de considerar o cuidado com o outro e com o meio ambiente. Para P4, cuidar do outro (do próximo) e do meio ambiente é uma forma de expressar uma atividade de cidadania, buscando exercer plenamente seus direitos e deveres. Aqui, é possível refletir sobre a dimensão socioambiental no âmbito jurídico. Conforme Kalil e Ferreira (2017), abordar a questão socioambiental é pensar em uma forma integradora de compreendê-la, a partir da ideia de que o ser-humano pertencente ao meio ambiente em uma visão de todo, preconizando, portanto, uma relação indissociável, interdependente e transversal entre os elementos social e ambiental. Esse é também um dos debates ambientais surgidos no séc. XXI e que pretende superar a visão tradicional de cidadania reduzida aos direitos, suscitando outras questões além daquelas relacionadas aos direitos de primeira e segunda geração, como os civis e políticos, e sociais, respectivamente. Gudynas (2009) esclarece que os elementos éticos, ecológicos e ontológicos seriam capazes de permear uma proposição mais ampla dessa perspectiva de cidadania, constituindo uma cidadania ecológica.

Verifica-se que a fala de P4 contém, diferentemente das de P1, P2 e P3 que recorrem, na ausência de um aprofundamento conceitual, aos direitos de primeira e segunda geração -, a ideia dos direitos de terceira geração (direitos difusos), aqueles surgidos na década de 1970 e que se referem ao coletivo da humanidade (MARTINS, 2004), ao meio ambiente sadio, aos direitos das minorias, propondo uma nova compreensão das questões ambientais por meio da educação e de um compromisso com o futuro. Nessa perspectiva, é cabível relacionar as críticas de Santos (2005) e Soffiati (2011), quando alegam que as constituições nacionais mais modernas abarcaram o 
Possibilidades socioambientais e interdisciplinares da cidadania a partir do que dizem alunos e professores de uma escola pública de ensino fundamental em Salvador-Bahia

equilibro ambiental ou ambiente sadio como direito do homem, fazendo com que o cidadão passasse a assegurar inclusive às gerações futuras, esses direitos; entretanto, o ambiente em si continua sem direitos.

$\mathrm{Na}$ escola analisada, a temática da cidadania é introduzida na formação dos alunos por meio de disciplinas específicas e nos projetos temáticos. O tema da cidadania está organizado nos conteúdos dos planos de aula e ensino do Eixo Temático de Cidadania, não tendo sido verificado nos outros Eixos Temáticos investigados. Esse ponto pode ser analisado mais cautelosamente a partir das respostas dos alunos sobre o tema. Quando solicitados a explicar o que entendiam sobre cidadania, 20\% dos alunos não souberam responder ${ }^{3}, 20 \%$ se referiram ao meio ambiente enquanto $60 \%$ mencionaram outros elementos. Os dados revelam que 20\% dos alunos que não souberam responder o que é cidadania foram alunos do $6^{\circ}$ ano, na mesma proporção dos $20 \%$ que citaram o meio ambiente para explicá-la. Do total deste grupo de 20 alunos, $40 \%$ deixaram em branco ou informaram não lembrar ou saber o que é cidadania. Ainda neste grupo, 40\% citaram diretamente o meio ambiente enquanto $20 \%$ definiram a cidadania mencionando outros elementos. Entre os alunos de $8^{\circ}$ e $9^{\circ}$ ano, $100 \%$ responderam o que é cidadania, sem fazer qualquer referência ao meio ambiente. Tentando entender esses dados, por vezes contraditórios, é preciso recordar que o Eixo Temático de Meio Ambiente é introduzido na formação dos alunos de ensino fundamental a partir do $6^{\circ}$ ano, enquanto que o Eixo Temático de Cidadania é aplicado somente a partir do $8^{\circ}$ ano. P4 informa que desde o $6^{\circ}$ ano os alunos se deparam com conceitos de cidadania e educação ambiental, mas pelo que foi observado em sala, apenas de forma superficial:

Infelizmente, a educação ambiental, a cidadania e outros valores que estão sendo passados pros meninos eles estão sendo a partir do sexto ano, então pra mim os meninos têm que começar a trabalhar com isso desde pequeno, desde a terceira série mesmo, da educação infantil, porque quando chega no oitavo ano a gente constrói todo o conhecimento o menino na verdade absorve o conhecimento mas ele não coloca em prática porque ele só estuda para aquele momento $(\mathrm{P} 4)$

P4 sinalizou que os conceitos gerais de cidadania e educação ambiental são introduzidos na formação desses alunos a partir somente do $6^{\circ}$ ano, o que de fato justificaria o percentual relativamente elevado de $40 \%$ de alunos dessas turmas que não souberam responder o que é cidadania. Levando em conta que $42,5 \%$ dos alunos das turmas pesquisadas se situam na faixa etária de 13-14 anos, e que $37,5 \%$ estão na faixa de 15-16 anos, ou seja, que 80\% dos alunos investigados têm 13 anos ou mais, questiona-se: é possível afirmar que a formação desses alunos introduz tardiamente conceitos e valores de cidadania? Se a resposta for sim, concorda-se com P4, tornando-se evidente a necessidade de uma revisão curricular dos Eixos Temáticos analisados, antecipando essa integração e oferecendo uma formação interdisciplinar antes mesmo do $6^{\circ}$ ano. Percebeu-se o esforço dos docentes em não limitar suas práticas educativas e curriculares aos conteúdos dos livros didáticos e documentos oficiais. A necessidade de incorporar a realidade e vivências dos alunos esteve presente nas falas de P1 e P4, por meio de respostas em momentos distintos, buscando uma cidadania para além de 
um posicionamento clássico ou tradicional, caminhando em direção às práticas do dia a dia desse cidadão construtor de suas próprias experiências:

Basicamente eu procuro criar os meios de vivência... da própria vida deles, nas práticas do dia a dia, principalmente envolvendo cidadania, no que ele faz, no próprio lixo de dentro da casa deles [...] (P1).

Então eu me baseio não só nessas informações, mas principalmente nas vivências do aluno, problemas que a gente vive o tempo todo, e aí eu coloco minhas aulas expositivas, posso colocar um texto escrito, peço principalmente pra depois que a gente traz a parte teórica, eles elaborarem uma parte prática, da forma que eles quiserem da forma criativa, ou através trazendo uma revista, um jornal, eles representando, e aí, pra que o lúdico entre também dessa forma, e eles consigam o aprendizado necessário (P4).

Tanto P1 quanto P4 afirmaram estimular as vivências e práticas da vida diária desses alunos, destacando uma confrontação da realidade diante dos problemas apresentados. Ainda assim, verificou-se que $70 \%$ dos alunos da turma $\mathrm{A}$ de $6^{\circ}$ ano, do Eixo Temático de Meio Ambiente, não souberam responder o que é cidadania: aliás, essa foi a turma que mais deixou respostas em branco ou com frases do tipo não sei ou não lembro; $30 \%$ dos que souberam responder mencionaram a necessidade de limpeza das ruas. Portanto, os alunos de $6^{\circ}$ ano estão começando a dar os primeiros passos na apreensão dos conceitos de cidadania, ainda que os mesmos façam referência ao meio ambiente para responder sobre o que é cidadania. Quanto à turma de P4 (Eixo Temático de Cidadania), 100\% dos alunos responderam o que é cidadania, sendo que $70 \%$ destes recorreram aos direitos e/ou deveres para defini-la, de modo a demonstrar elementos teóricos sobre o que deve ou não ser feito na vida em sociedade, sem mencionar qualquer relação reflexiva, crítica ou transformadora.

Nesse sentido, é importante lembrar que o processo de "educar para a cidadania planetária é debater assuntos como meio ambiente, desigualdade social, porém, procurando uma compreensão global dos conflitos, identificando os acontecimentos como interdependentes" (OLIVEIRA, 2014, p. 282-283). As respostas dos alunos, especialmente as da turma de $9^{\circ}$ ano, sinalizaram elementos importantes de uma cidadania ativa e participativa, como a solidariedade e o respeito entre as pessoas; atitudes de bondade e amor ao próximo; o sujeito que possui ética e respeito na sociedade, dentre outros. Quando solicitados a explicar o que são os direitos e os deveres do cidadão, a maioria dos alunos respondeu (87,5\%). Dos que não souberam responder $(12,5 \%)$, $10 \%$ foram estudantes de $6^{\circ}$ ano. Verificou-se que as respostas dos alunos apontaram mais deveres do que direitos, sendo que os deveres relatados fizeram menção, em sua quase totalidade, à obrigação de não jogar lixo nas ruas e a manter o ambiente limpo, conforme observado também na fala de P3:

[...] pra você ser um cidadão, participar da sociedade, você está envolvido no seu ambiente, que faz parte, que a gente até conversou sobre isso, a questão do lixo, você colocar nos horários certos, não deixar ao ar livre $[. .].(\mathrm{P} 3)$.

Para P2, o cidadão deve ser convocado para a responsabilidade e o cuidado pelo meio ambiente, na tarefa em buscar soluções, tornando-se, portanto, um cidadão integral e praticando ações de cidadania. 
Possibilidades socioambientais e interdisciplinares da cidadania a partir do que dizem alunos e professores de uma escola pública de ensino fundamental em Salvador-Bahia

Isso porque a pessoa que é cidadã ela provavelmente irá cuidar bem do meio ambiente, não vai jogar lixo à toa, não vai cortar as árvores, não vai praticar queimadas, enfim, resumindo, ela vai fazer tudo para preservar o meio ambiente $(\mathrm{P} 2)$.

Este novo relato de $\mathrm{P} 2$, em contradição à sua primeira resposta, na qual afirmava que a cidadania é uma disciplina que deve estimular os alunos a conhecer seus direitos e deveres, expõe uma cidadania imbricada com o meio, ao incorporar a responsabilidade e a participação individual nesse processo. Por outro lado, repassa para o cidadão a tarefa incondicional de preservar o meio ambiente, sem estabelecer uma reflexão crítica que suscite os processos produtivos que o levam, isolada ou coletivamente, a cortar árvores ou a realizar queimadas, características predominantes do modelo atual de desenvolvimento econômico. Tal perspectiva, diante das incertezas socioambientais da atualidade, não invalida as ações de proteção da natureza. Contudo, retira parte do saber que poderia estar por trás dessas ações, contribuindo para que não se tornem meras reproduções do que dizem os professores e os livros didáticos, fazendo recordar a educação bancária sumariamente criticada por Freire (1987), quando se refere ao depósito compulsório de conhecimentos nos educandos sem exigir-lhes reflexão, emancipação ou autonomia:

Dessa maneira, a educação se torna um ato de depositar, em que os educandos são os depositários e o educador o depositante [...] em lugar de comunicar-se, o educador faz 'comunicados' e depósitos que os educandos, meras incidências, recebem pacientemente, memorizam e repetem (FREIRE, 1987, p. 58).

Algumas das obrigações e deveres relativos à cidadania foram retratadas em diversas falas de alunos, com destaque para o papel do cidadão em manter a ordem e respeitar as leis, votar corretamente, respeitar os mais velhos e cumprir com a limpeza do bairro. Com isso, muitos desses princípios acabaram recorrendo aos valores de bem comum na vida em sociedade, como os direitos sociais e os deveres políticos, tal qual sistematizado por Santos (2005). A autora diz que a cidadania liberal, predominante no século XX, está mais próxima de um status de membro do que de prática, levando o cidadão a exercer seus direitos naturais, individuais e inalienáveis, mas cobrando-lhe na forma de exercer seus deveres políticos e civis, como votar, pagar impostos, obedecer às leis, prestar serviço militar, dentre outras obrigações.

A complexidade dos problemas ambientais enfrentados na modernidade e as novas reivindicações das sociedades na conjugação dos direitos de primeira, segunda e terceira dimensões, particularmente pela ênfase conferida à proteção do 'macrobem ambiental', tem sido um dos importantes vetores de mudanças comportamentais que fizeram florescer uma preocupação ética e socioambientalmente responsável, o que tem ensejado a configuração de um novo modelo de Estado condizente com essa preocupação (KALIL; FERREIRA, 2017, p. 342).

Portanto, infere-se que a formação desses alunos tem situado a cidadania mais como uma proposta disciplinar para o exercício cívico e político dos deveres do cidadão do que um vetor de conhecimento que implique ação, reflexão e a construção de valores a partir dos diversos elementos que a compõem. Assim, o aluno não percebe 
que a realidade do Cabula e entorno pode ser transformada, mas o ambiente tem que ser cuidado e mantido limpo, ainda que aquele que cuida não saiba refletir exatamente sobre como ou para quê fazê-lo. Por consequência, deve-se jogar lixo no lixo e cuidar do ambiente, sem uma aparente representação dos direitos e deveres que englobem as relações entre a sociedade e a natureza ou os direitos ambientais, integrados à visão de uma cidadania participativa. Nessa vertente, ganharia lugar uma abordagem socioambiental, capaz de se desenvolver integralmente em meio às relações dialógicas produzidas em sala de aula, conforme ressaltam Freire, Nascimento e Silva (2006). A partir de um enfrentamento da realidade, o aluno não dissocia os fenômenos econômicos e sociais de suas práticas cidadãs, tendo em vista ser capaz de interpretar e problematizar questões relevantes de modo individual - portanto enquanto indivíduo - e coletivo - já que vivendo em sociedade. Essas possibilidades indicam caminhos nos quais os alunos poderiam relacionar e ao mesmo tempo distinguir as diferentes dimensões que fazem parte de suas realidades, dando maior significado ao ensino e à aprendizagem.

\section{Considerações finais}

O elemento mais citado e apontado pelos alunos e parte dos professores das turmas investigadas voltou-se para a questão dos resíduos sólidos, como o tratamento correto e adequado do lixo e a necessidade de não ser jogado nas ruas. Desse modo, em sala de aula e na escola, o lixo não deve ser tratado apenas como um problema meramente ambiental que se encontre permanentemente isolado e separado de um problema social. Isso acaba dificultando a percepção dos alunos de que a realidade a ser transformada é aquela que exige a participação e a organização de comunidades e cidadãos em prol de políticas públicas mais eficazes. Portanto, a cidadania exercida a partir da visão exclusiva dos direitos e deveres, ao reduzir as relações entre indivíduos, sociedade e natureza, não irá colaborar para que o aluno resolva questões que envolvam diretamente o meio ambiente, já que essa cidadania se encontra desvinculada deste. Conforme visto, para a maioria dos alunos, a cidadania tem uma função normativa, concentrada nos direitos e deveres a serem seguidos, correndo o risco de serem assimilados como deveres punitivos. Para tanto, os deveres têm que ser cumpridos e os direitos têm que ser buscados e conquistados. Na prática, porém, o aluno não consegue distinguir um direito social de um ambiental, na contrapartida de um dever cívico e político.

Assim, o aluno aprende em sala de aula que um bom cidadão é aquele que conserva o meio ambiente sempre limpo e constata que em seu bairro tem gente mal -educada, desmatando a natureza e queimando o lixo em local inapropriado, desrespeitando as regras de cumprimento dos deveres, tornando-se, portanto, maus cidadãos. Mas o que há assim de tão importante nesses deveres e direitos? Quais as dimensões econômicas, ecológicas, sociais, ambientais, sociais, culturais, territoriais e espirituais que abrangem as relações entre os seres humanos, os ecossistemas, os indivíduos e as sociedades? São questões que precisam ser esclarecidas e socializadas nas sociedades e na formação dos alunos, para não tornar estéreis de transformação as práticas de cidadania. É sabido que, para que se possa transformar uma dada realidade em sua dinâmica, é preciso ter modelos sociais e culturais de referência de como transformá-la e o 
Possibilidades socioambientais e interdisciplinares da cidadania a partir do que dizem alunos e professores de uma escola pública de ensino fundamental em Salvador-Bahia

conhecimento de seu contexto histórico e político. Nesse sentido, percebe-se que uma cidadania ampliada e contextualizada com outras questões - como as socioambientais - mostra-se repleta de desafios e possibilidades nas escolas públicas de ensino fundamental, na ideia de poder alcançar os objetivos de uma formação efetivamente cidadã.

\section{Referências}

BRASIL. Secretaria de Educação Fundamental. Temas Transversais: meio ambiente. Brasília: $\mathrm{MEC} / \mathrm{SEF}, 1998$.

BRASIL. Ministério da Educação. Ministério do Meio Ambiente. Consumo sustentável: manual de educação. Brasília: Consumers International/MMA/MEC/IDEC, 2005.

DIAS, D. S. S.; CARNEIRO, S. M. M. Contribuições para a formação da consciência socioambiental cidadã nos anos iniciais do ensino fundamental. In: SEMINÁRIO DE PESQUISA EM EDUCAÇÃO DA REGIÃO SUL - ANPED SUL. 9. 2012. Anais eletrônicos... Disponível em: <www.ucs.br/etc/conferencias/index.php/anpedsul/9anpedsul/.../830>. Acesso em: 23 ago. 2015.

EDNIR, M.; MACEDO, D. M. Planetary citizenship and curriculum: Schools from three continents learn through diversity. Field Actions Science Reports [Online], Special Issue 3, 2011. Disponível em: <http://factsreports.revues.org/1038> Acesso em: 09 jun. 2015.

FERNANDES, R. B.; PENA, J. S.; LIMA, J. de B. Cabula: entre produção do espaço e especulação. In: SILVA, Francisca de Paula Santos da (Org.). Turismo de base comunitária e cooperativismo: articulando pesquisa, ensino e extensão no Cabula e entorno. Salvador: EDUNEB, 2013. p. 53-68.

FREIRE, P. Pedagogia do oprimido. 17 ed. Rio de Janeiro: Paz e Terra, 1987.

FREIRE, J. T.; NASCIMENTO, M. de F. F.; SILVA, S. A. H. Diretrizes Curriculares de Educação Ambiental: as escolas da Rede Municipal de Ensino de Salvador. Salvador: SMEC, 2006.

FRÓES BURNHAM, T. Pesquisa multirreferencial em educação ambiental: bases sócio-culturais-político-epistemológicas. Pesq. Educ. Ambient., v. 1, n. 1, p. 73-92, jul./dez. 2006.

GADOTTI, M. Pedagogia da terra: Ecopedagogia e educação sustentável. In: Paulo Freire y la agenda de la educación latinoamericana en el siglo XXI. Buenos Aires: CLACSO, 2001.p. 81-132.

GIL, A. C. Métodos e técnicas de pesquisa social. 5. ed. São Paulo: Atlas, 1999.

GUDYNAS, E. Ciudadanía ambiental y meta-ciudadanías ecológicas: revisión y alternativas en América Latina. Desenvolvimento e Meio Ambiente, n. 19, p. 53-72, jan./jun. 2009.

KALIL, A. P. M. C.; FERREIRA, H. S. A dimensão socioambiental do estado de direito. Veredas do Direito, Belo Horizonte, v. 14, n. 28, p. 329-359, jan./abr. 2017. Disponível em: <http:// www.domhelder.edu.br/revista/index.php/veredas/article/view/1010/0> Acesso em: 12 dez. 2017.

MARTINS, S. R. Construindo a cidadania ambiental. Texto base para os Núcleos de Educação Ambiental da Agenda 21 de Pelotas - RS. Formação de coordenadores e multiplicadores socioambientais. Santa Catarina: UFSC, 2004.

OLIVEIRA, S. P. Biocentrismo e ecopedagogia: a educação como ferramenta para a cidadania planetária. Direito e Desenvolvimento, v. 5, n. 2, p. 271-286, jun. 2014. Disponível em: <https://periodicos.unipe.br/index.php/direitoedesenvolvimento/article/view/271>Acesso em: 12 dez. 2017. 
SANTOS, M. E. V. M. dos. Cidadania, conhecimento, ciência e educação CTS. Rumo a "novas" dimensões epistemológicas. Revista CTS, v. 2, n. 6, p.137-157, dez. 2005.

SEVERO, C. G. Sobre a formação da cidadania nos documentos oficiais e nos materiais didáticos e a importância dos gêneros discursivos. Odisséia, n. 1, p. 1-14, 2008.

SOFFIATI, A. Fundamentos filosóficos e históricos para o exercício da ecocidadania e da ecoeducação. In: LOUREIRO, C. F. B.; LAYRARGUES, P. P.; CASTRO, R.S. de (Orgs.). Educação ambiental: repensando o espaço da cidadania. 5. ed. São Paulo: Cortez, 2011. p. 27-72.

VERGARA, S.C. Métodos de coleta de dados no campo. São Paulo: Atlas, 2009.

\section{Notas}

1 “[...] el concepto convencional de ciudadanía es otra de las expresiones de una visión dual que diferencia los seres humanos de la Naturaleza. Ciudadanía inevitablemente refiere a la ciudad, a una 'polis', la que está por fuera de la Naturaleza, la que puede ser dividida en componentes a ser manipulados y aprovechados. El ciudadano en tanto 'civilizado' debe controlar y aprovechar los espacios silvestres o 'salvajes'. Estas posturas propias de la modernidad, donde las concepciones de ciudadano y ambiente se determinan mutuamente" (GUDYNAS, 2009, p. 65).

${ }^{2}$ Todos os sujeitos de pesquisa assinaram o Termo de Consentimento Livre e Esclarecido (TCLE) do Conselho de Ética em Pesquisa.

${ }^{3}$ Respostas em branco ou com frases do tipo: Não sei ou Não lembro foram consideradas de alunos que não souberam responder, entrando no cômputo geral de cada turma.

* Pós-doutoranda pelo Programa de Pós-Graduação em Difusão do Conhecimento (DMMDC) da Faculdade de Educação da Universidade Federal da Bahia, Salvador, Bahia, Brasil.

\section{Correspondência}

Isabelle Pedreira Déjardin - Universidade Federal da Bahia, Faculdade de Educação. Av. Reitor Miguel Calmon, Vale do Canela. CEP: 40110-100. Salvador, Bahia, Brasil.

E-mail: belledejardin@hotmail.com

Recebido em 14 de outubro de 2016

Aprovado em 19 de março de 2018 